\title{
Velkakriisi kouraisee myös EU:n maataloutta
}

\author{
Kyösti Pietola ${ }^{1)}$, Sami Myyrä2) ja Anna-Maija Heikkilä ${ }^{3)}$ \\ ${ }^{1)}$ MTT Taloustutkimus, Latokartanonkaari 9, 00790 Helsinki, kyosti.pietola@mtt.fi \\ ${ }^{2)}$ MTT Taloustutkimus, Latokartanonkaari 9,00790 Helsinki, sami.myyra@mtt.fi \\ ${ }^{3)}$ MTT Taloustutkimus, Latokartanonkaari 9,00790 Helsinki, anna-maija.heikkila@mtt.fi
}

\section{Tiivistelmä}

Rajalliset resurssit kuten peltomaa ja investointien rahoituslähteet ratkaisevat maatilan ja koko maataloustoimialan kehitysmahdollisuudet. Maatilan rahoitusmahdollisuuksien ylärajan muodostavat tilan aikaansaaman vuosituoton lisäksi maatilan velkaantuneisuus sekä rahoittajien esittämät vakuusvaatimukset. Erityisesti perheviljelmät kokevat nämä rahoituksen rajoitteet ulkoapäin annetuiksi, sillä ne eivät voi kerätä markkinoilta rahoitusta osakeyhtiöiden tapaan. Maatilan rahoitusmahdollisuuksien yläraja riippuu olennaisesti paikallisten rahamarkkinoiden kyvystä arvioida maatalousvarallisuuden arvo ja investointien rahoitukseen liittyvät riskit oikein.

Tässä tutkimuksessa tarkasteltiin eurooppalaisten maatilojen pääomia, velkaantuneisuutta sekä vieraasta pääomasta maksettuja korvauksia. Aineistona käytettiin laajaa ja EU:n laajuisesti yhtenäisin perustein kerättyä FADN-aineistoa sekä Euroopan keskuspankin (EKP) tilastoja. Eri maiden välillä havaitut erot maatalousvarallisuuden arvioinnissa joko rajaavat tai mahdollistavat maatilojen aggressiivisia investointisuunnitelmia. Erot rahoituslaitosten antamissa mahdollisuuksissa ovat maiden välillä yllättävän suuria. Tulokset osoittavat, että maatalouden investointeja ja kehittämistä koskevat strategiat ovat olleet eri maissa erilaiset ja maatalouden rahoitusmarkkinat ovat erittäin segmentoituneet eri maiden välillä.

Tanskan maatalouden keskimääräinen velkaisuusaste on kivunnut jo 50 prosenttiin, ja Hollannissakin se ylittää 40 prosenttia. Tanskalainen viljelijä maksoi vuonna 2008 luotoistaan keskimäärin 7 prosentin korkoa, kun suomalainen viljelijä maksoi lainoistaan tuolloin keskimäärin 4,1 prosentin korkoa ja kreikkalaisen viljelijän maksama korko oli kivunnut yli 10 prosenttiin. Kreikkalaisten viljelijöiden kaikista varoista vieraan pääoman osuus oli vuonna 2008 vain 0,6 prosenttia. Pienestä velkamäärästä johtuen korkojen nousu ei yksin aiheuta ylitsepääsemätöntä ongelmaa Kreikan maataloudelle.

Pohjois-Euroopan maiden maataloussektorit ovat keskimääräistä velkaantuneempia. Suomi ja Ruotsi sijoittuvat 28 prosentin velkaisuusasteillaan EU:n kahdeksan velkaantuneimman maan joukkoon.

Asiasanat velkakriisi, rahoitus, pääomahuolto 


\section{Johdanto}

Jos Euroopan rahoituskriisi edelleen heikentää valtioiden kykyä hoitaa velkansa ja rapauttaa pankkien välistä luottamusta, ongelmat alkavat tunkeutua väistämättä myös maatalouden rahoitukseen ja pääomahuoltoon. Syynä on se, että nykyaikaisen maatalouden pääomahuolto ja rahavirrat ovat osa kansainvälisiä pääomamarkkinoita, jotka kytkeytyvät sekä valtioiden että pankkien varainhankinnan kautta toisiinsa. Euroopan maatilat lainaavat vierasta pääomaa yhä enemmän ja ovat sen vuoksi kytköksissä kansainväliseen rahamarkkinaan. Jos rahan liike maailmalla hidastuu ja hinta nousee, se heijastuu ennen pitkää väistämättä myös maatalouden rahoitukseen. Viljelijöiden pääsy uusiin luottoihin vaikeutuu ja lainarahan hinta nousee.

\section{Korot kääntyneet nousuun}

Maatalousluottojen korot ovat Euroopassa pääpiirtein seuranneet muita keskeisiä korkoja. 1990-luvun alun laman jälkeen korot laskivat vuoteen 2006 saakka ja kääntyivät vuonna 2007 selvään nousuun (Kuva 1). Vuonna 2008 maatalouden korot olivat noin 4,5 prosenttia, mikä on samaa suuruusluokkaa kuin Euroopan keskuspankin (EKP) joukkovelkakirjojen korko. Maatalousluottojen korko oli vuonna 2008 jopa hieman alhaisempi kuin kotitalouksien ottamien uusien asuntoluottojen korko ja Euribor-korko pankkien välisillä tukkumarkkinoilla.

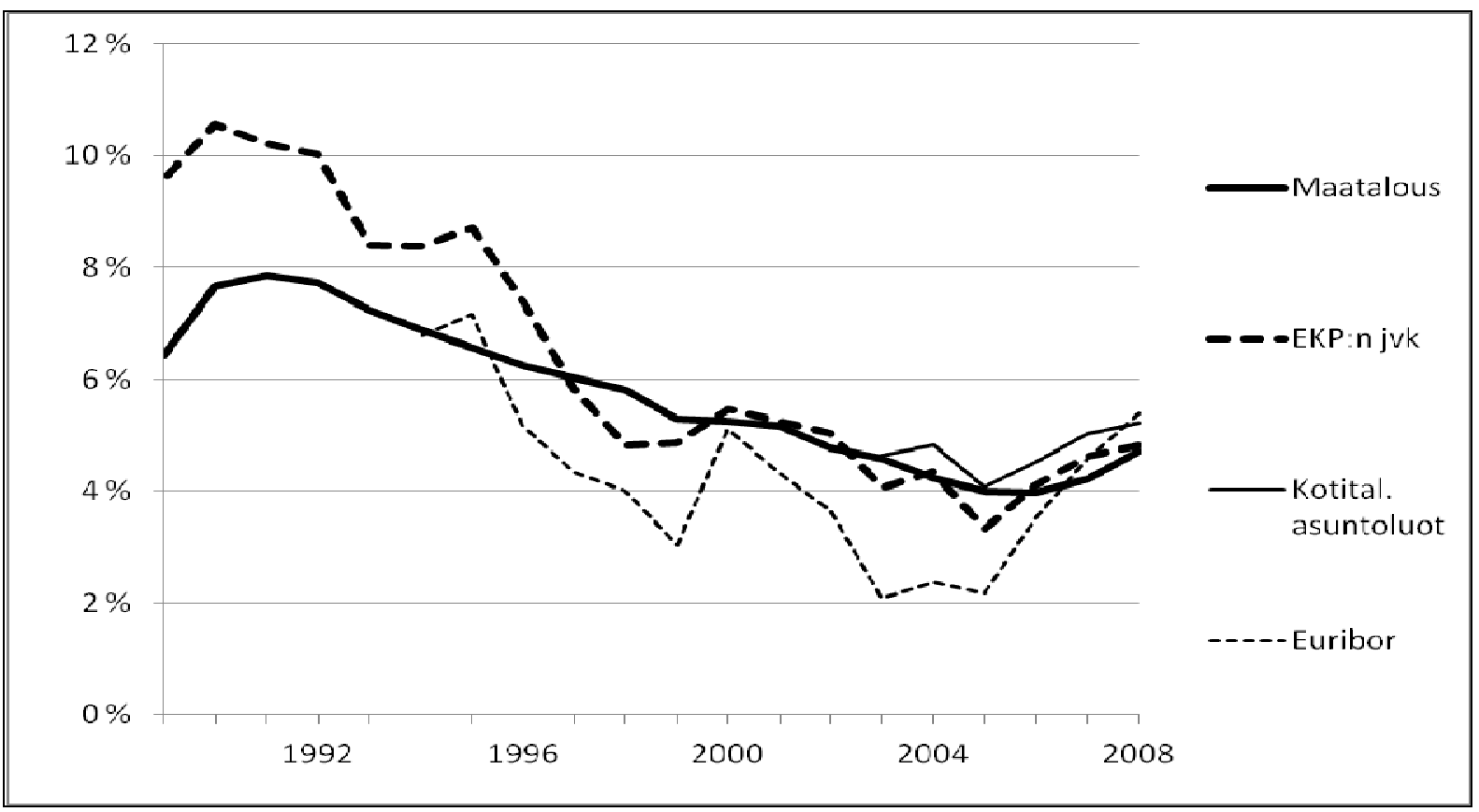

Kuva 1. Maatalousluottojen, EKP:n joukkovelkakirjojen ja asuntoluottojen korot sekä Euribor korko 1989-2008 (European Central Bank; FADN).

\section{Maatalous velkaantumassa}

Merkillepantavaa on, että EU:n maatalouden velkataakka on viime vuosina kasvanut tuplavauhtia verrattuna 1990-luvun lama-ajan pahimpiin vuosiin. EU:n maatalouden keskimääräinen velkaisuusaste nousi yhdessä vuodessa, vuodesta 2007 vuoteen 2008 peräti 4 prosenttiyksikköä, 14 prosentista 18 prosenttiin (Kuva 2). Edellisen, 1990-luvun alun laman aikaan maatalouden velkaisuusaste nousi vuodessa pahimmillaan alle puolet tästä. Velkaantumisen nopeaa nousua ei voi selittää yksin investoinneilla, koska Euroopan maatalouden nettoinvestoinnit ovat keskimäärin tarkastellen olleet jo pitkään kutakuinkin nollassa niin, että korvausinvestoinnit ovat vastanneet enintään poistoja. 


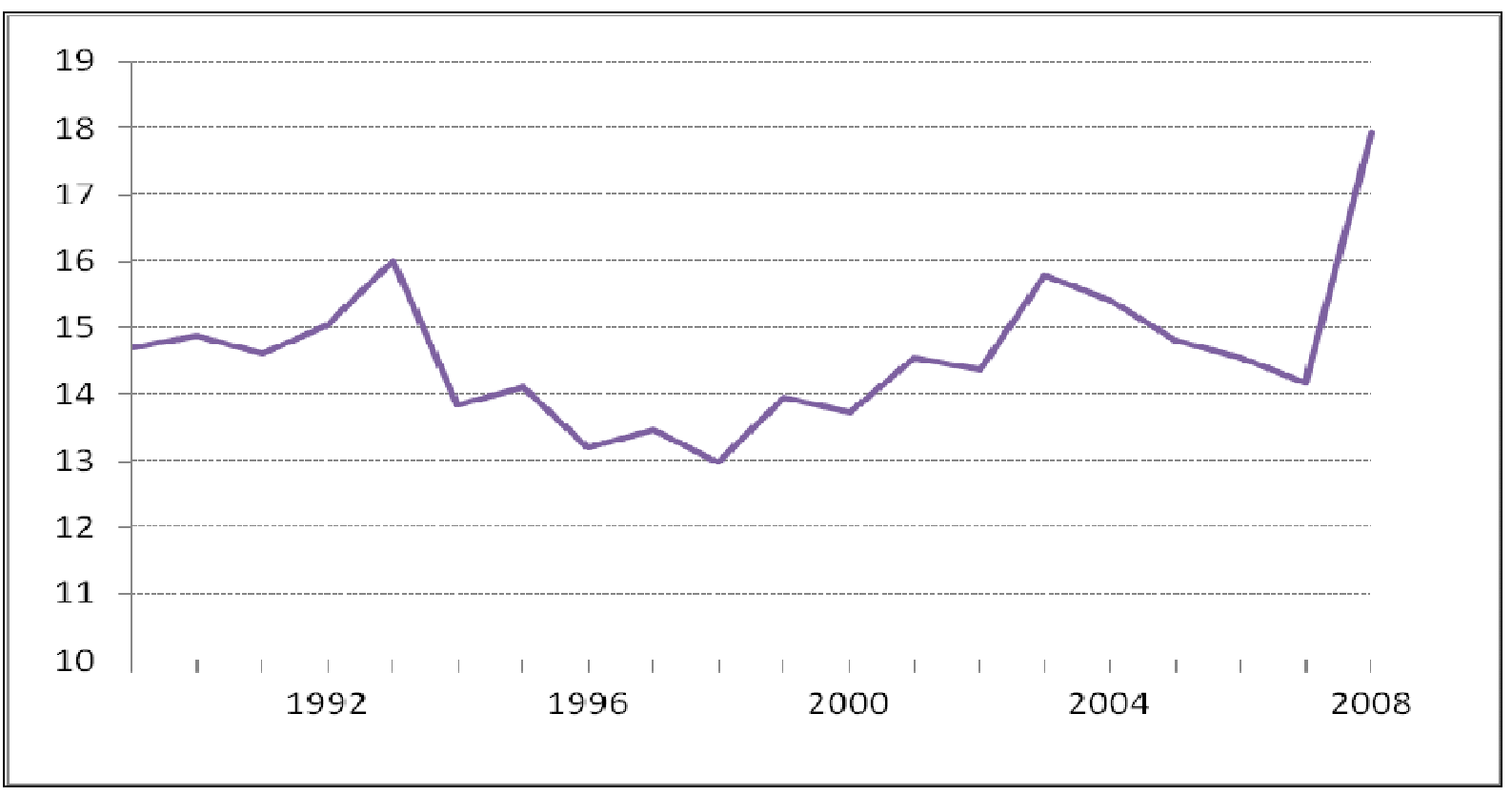

Kuva 2. Maatilojen luottojen osuus (\%) niiden kokonaispääomasta (financial leverage) EU:ssa keskimäärin vuosina 1989-2008 (FADN).

\section{Kreikan ja Espanjan viljelijät velattomia}

Maatalouden velkaantuminen jakautuu EU maiden kesken erittäin epätasaisesti, mutta jakauma ei kuitenkaan noudata millään tavoin valtioiden velkaantuneisuutta eikä valuutta-alueiden rajoja. Kaikkein pahimpien valtionvelkaongelmien kanssa painiskelevien maiden, kuten Kreikan ja Espanjan, maataloudet ovat käytännössä velattomia. Valtion velkaantumisesta aiheutuvan maariskin laukeaminen ei suoraan aiheuta dramaattista velkakriisiä näiden maiden viljelijöille. Esimerkiksi kreikkalaisten viljelijöiden kaikista varoista vieraan pääoman osuus oli vuonna 2008 vain 0,6 prosenttia (Kuva 3). Niinpä korkojen nousu ei yksin aiheuta ylitsepääsemätöntä ongelmaa Kreikan maataloudelle, vaikka sen korot olivat jo vuonna 2008 nousseet yli kymmeneen prosenttiin. Riskit realisoituvat näissä maissa valtion kassakriisin ja tukipolitiikan aiheuttamien tuloriskien kautta, eikä niinkään taseessa olevan velkariskin kautta.

Espanjassa vastaava velkaisuusaste oli 2,2 prosenttia, ja Irlannissakin se oli alle 5 prosenttia. Italian maataloudesta puuttuivat tutkimusta tehtäessä tilastotiedot, joten sitä ei saatu mukaan tähän vertailuun. Sekin voi toki kieliä yleisestä taloudenpidon tarkkuudesta, että tilastot valmistuvat liian hitaasti.

\section{Suomi ja Ruotsi kahdeksan velkaantuneimman joukossa}

Pohjois-Euroopan maiden maataloussektorit ovat keskimääräistä velkaantuneempia. Suomi ja Ruotsi sijoittuvat 28 prosentin velkaisuusasteillaan kahdeksan velkaantuneimman maan joukkoon (Kuva 3). Kotieläintalouden rakennekehitys ja investoinnit ovat nostaneet maatilojen velkaisuutta näissä maissa. Esimerkiksi Suomessa lypsykarjatalouteen erikoistuneiden tilojen investoinnit ovat jatkuneet voimakkaina aivan viime vuosiin saakka ja koska lypsykarjatalouden osuus on koko toimialasta suuri, nämä investoinnit näkyvät myös koko toimialan luvuissa. 


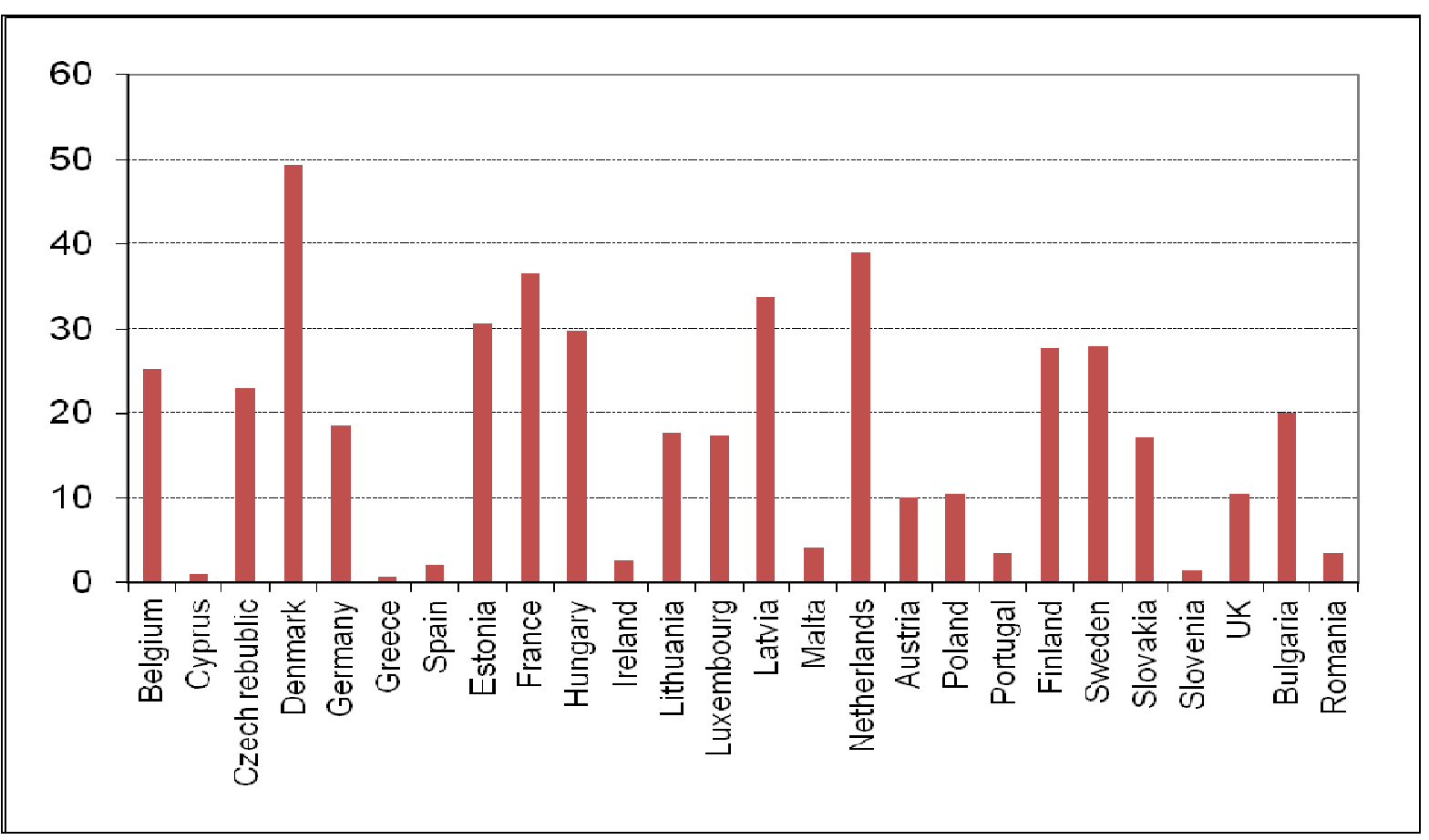

Kuva 3. Maatilojen velat (\%) niiden kaikista varoista eri EU-maissa keskimäärin vuonna 2008 (FADN).

\section{Maatalousvelka suurin Tanskassa ja Hollannissa}

Maatalousalan pahimmat velkojen ja rahoituskriisien keskittymät löytyvät EU:ssa niin sanotusta Lontoon ryhmästä, joka on ennen ajanut maatalouden tukipolitiikan alasajoa ja maataloustuotannon keskittämistä kilpailukykyisimpiin erittäin pääomavaltaisiin yrityksiin.

Tanskan maatalouden keskimääräinen velkaisuusaste on kivunnut jo 50 prosenttiin, ja Hollannissakin se ylittää 40 prosenttia. Tanskalainen viljelijä maksoi vuonna 2008 luotoistaan keskimäärin 7 prosentin korkoa, kun suomalainen viljelijä maksoi lainoistaan tuolloin keskimäärin 4,1 prosentin korkoa ja kreikkalaisen viljelijän maksama korko oli kivunnut yli 10 prosenttiin (Kuva 4).

Kaikkien maatalousluottojen korko oli koko EU:ssa vuosina 2004-2008 keskimäärin 4,1\% (Kuva 4). korkojakaumalle on tunnusomaista se, että suurimmassa osassa maista korot ovat olleet lähellä keskiarvoa, mutta jakauman hännillä erot ovat suuret. Eräissä maissa, kuten Kreikassa, korot olivat yli kaksinkertaiset keskiarvoon verrattuna. Alhaisten korkojen kohdalla puolestaan rakenneohjelmien kautta maksettu korkotuki on laskenut maatalouden maksettavaksi jäävää nettokorkoa oleellisesti. Korko oli alhaisin Tsekissä.

Kun maatalouden maksamia korkoja verrataan kotitalouksien asuntolainoista maksamiin korkoihin nähdään, että eräissä maissa viljelijät maksavat lainoissaan jo merkittäviä riskilisiä. Riskilisä on korkein (5\%) Eestissä. Myös tanskalainen viljelijä maksoi kotitalouksien asuntoluottoihin verrattuna merkittävää 3,5 prosenttiyksikön riskilisää (Kuva 5). Kuten yllä todettiin rakenneohjelmien kautta maksettava korkotuki alentaa eräissä maissa maatalousluottojen korkoja niin että ne jäävät kotitalouksien maksamia korkoja alemmiksi. 


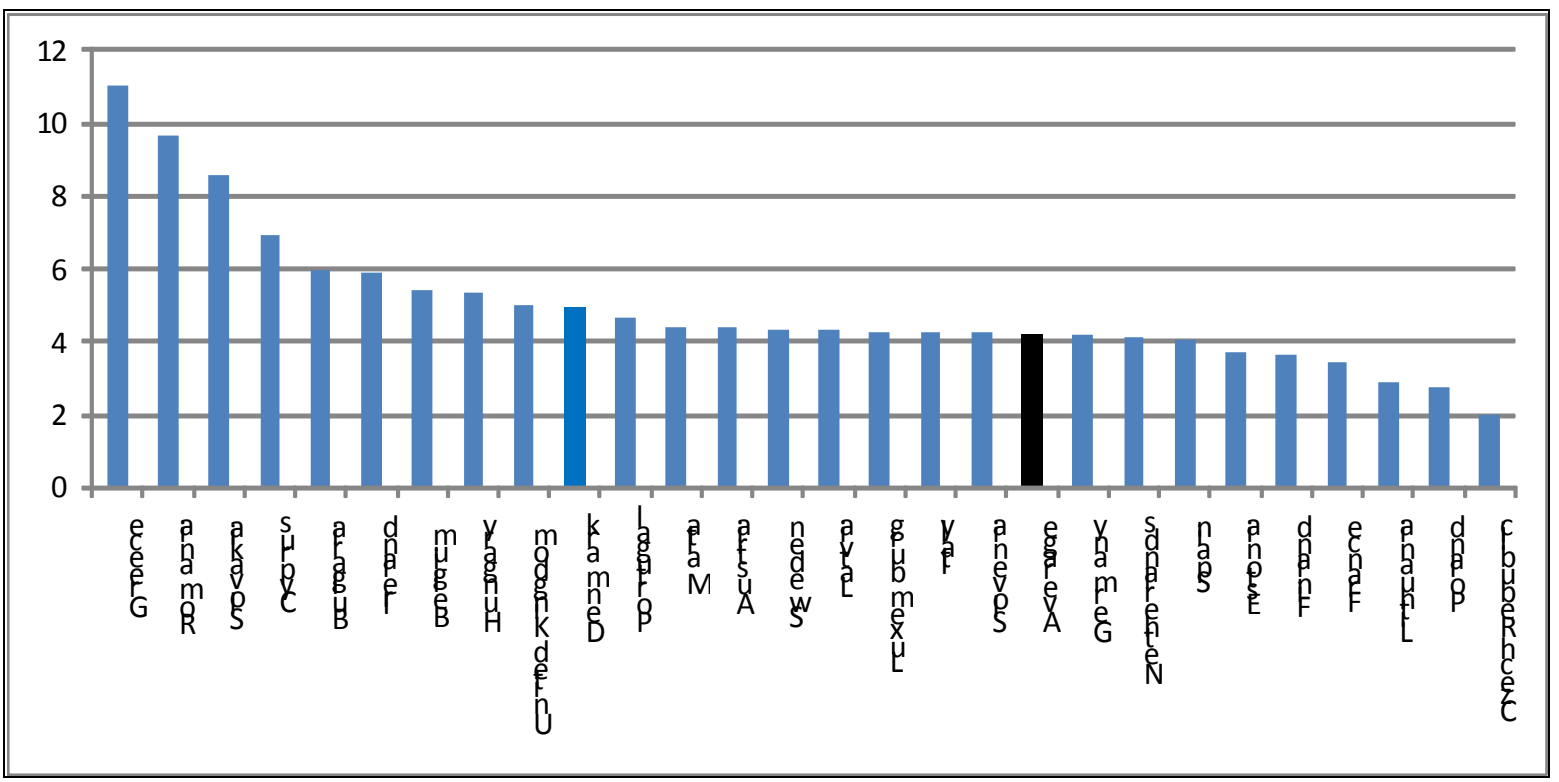

Kuva 4. Maatalousluottojen korko (\%) eri EU-maissa 2004-2008 viiden vuoden maakohtaisena geometrisena keskiarvona (FADN)

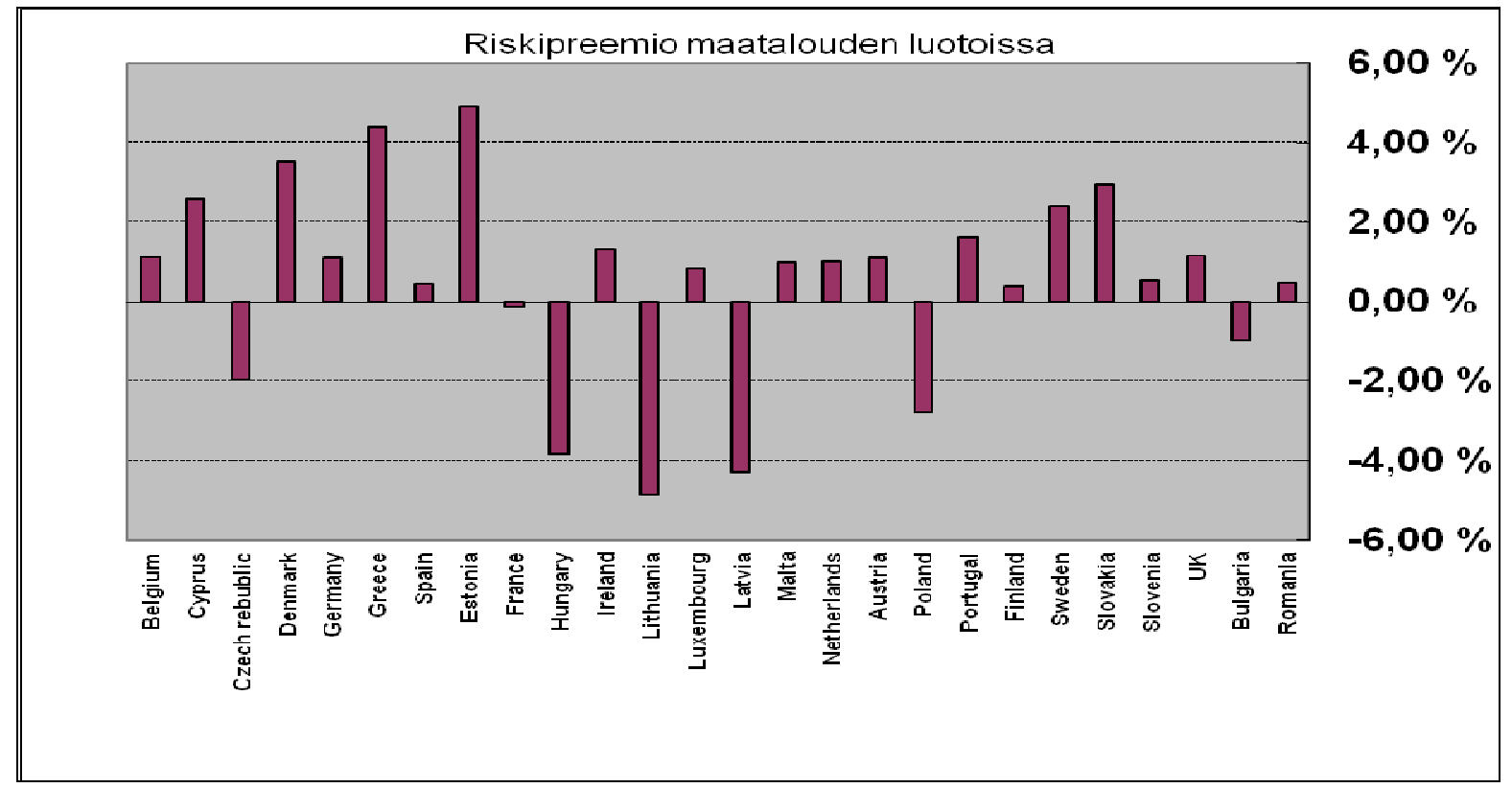

Kuva 5. Maatalousluottojen riskilisä eri EU-maissa. Preemio on laskettu vähentämällä maatalousluottojen korosta kotitalouksien maksama uusien asuntoluottojen korko (European Central Bank, FADN).

\section{Tanskassa hintakuplaa?}

Maatalouskiinteistöjen ja viljelymaan arvostuksissa on myös maittain suuria eroja. Esimerkiksi Ranskassa pellon verotusarvot olivat vuonna 2008 maltilliset 5474 euroa/ha, kun Tanskassa pelto arvostettiin samaan aikaan jo keskimäärin 25000 euron hehtaarihintaan. Tanskalainen viljelijä on saanut taseisiinkin kirjattujen kiinteistöjen hintojen nousun kautta pääomalleen jo kahdenkymmenen vuoden ajan keskimäärin yhdeksän prosentin tuoton. Tämä odotettuihin myyntivoittoihin perustuva tuotto, joka ei ole investoivalle aktiiviviljelijälle koskaan realisoitunut rahana, on kannustanut ostamaan mm. peltoa velkarahalla kovaan hintaan. Investoija on odottanut, että jo yksin hintojen nousu ylittää selvästi velkojen korkokustannuksen. 
Kahtena viimeisenä vuotena pellon hehtaarihintoja on nostettu tanskalaistilojen taseissa lähes kymmenellä tuhannella eurolla vuodessa. Väistämättä herää kysymys, että onko pellon arvostusta vedätetty tarkoituksella ylöspäin velkaongelman siirtämiseksi tuonnemmaksi. Ilmeistä on, että jossain vaiheessa tämä ketjukirje katkeaa ja Tanskan maatalous törmää maatalouskiinteistöjen korkean arvostustason ja hintakuplan aiheuttamiin yllätyksiin.

Tanskan tavoin myös Hollannissa kiinteistöjen hinnat ovat maatilojen taseissa korkeat, mutta yksi maailman kovimmista väestöpaineista pitänee Hollannissa maan hinnat korkealla myös jatkossa. Ranska puolestaan edustaa maaryhmää, jossa kirjaukset maatalouskiinteistöjen arvonnousuista ovat olleet maltillisia. Melko korkeaan, 37 prosentin velkaantumisasteeseen ei todennäköisesti sisälly yhtä suurta maatalouskiinteistöjen hintakuplaa tai -riskiä kuin Tanskassa.

\section{Miten maatalouden rahoituksen käy jos kriisi leviää Ranskaan?}

Mikäli valtioiden velkakriisi leviäisi myös Ranskaan, sillä olisi todennäköisesti merkittäviä suoria vaikutuksia myös EU:n maatalouden vakauteen ja pääomahuoltoon. Peräti 23 prosenttia koko EU:n maatalouden kaikista veloista on Ranskassa. Hollanti tulee toisena ja Tanska kolmantena, molemmat vajaan 20 prosentin velkaosuuksilla. Ranskalla, Hollannilla ja Tanskalla on yhdessä yli 60 prosenttia kaikista maataloussektorien veloista EU:ssa. EU:n maatalouden kestävyys rahoituskriisiä vastaan riippuukin paljolti siitä, mitä näissä kolmessa maassa tapahtuu.

\section{Kirjallisuus}

Tulokset perustuvat EU:n FP7 ohjelmasta rahoitettuun tutkimukseen nimeltä "Comparative Analysis of Factor Markets for Agriculture accross the Member States". Lisätietoja löydät tutkimusohjelman verkkosivulta osoitteesta http://www.factormarkets.eu/ 